\title{
OJS OPEN

\section{RECURSOS MULTIDIDÁTICOS PARA A EDUCAÇÃO GEOGRÁFICA NO ENSINO MÉDIO: REFLEXÕES E VIVÊNCIAS DO ESTÁGIO SUPERVISIONADO}

\author{
Nádson Ricardo Leite de Souza ${ }^{1}$, Nathália Rocha Morais², Maria do Socorro Silva \\ Salvador $^{3}$
}

Mestrando pelo Programa de Pós-Graduação em Geografia (PPGG/CCEN) da Universidade Federal da Paraíba (UFPB), em João Pessoa, Brasil. E-mail: nad_ric@hotmail.com; http://orcid.org/0000-0002-87443917

Doutoranda pelo Programa de Pós-Graduação da Universidade Federal da Paraíba (UFPB), Campus I, João Pessoa, PB. Professora substituta do Departamento de Geografia da Universidade Estadual da Paraíba (UEPB), em Campina Grande, PB, Brasil. E-mail: nathalia_rochamorais@hotmail.com; http://orcid.org/0000-0002-4590-4041

Mestranda pelo Programa de Pós-Graduação da Universidade Federal da Paraíba (UFPB), Campus I, João Pessoa, Brasil. Graduada em Licenciatura em Geografia pela Universidade Estadual da Paraíba (UEPB), Campus I, Campina Grande, PB. E-mail: maria.salvador6991@gmail.com; http://orcid.org/0000-00026777-9317

Artigo recebido em 26/06/2020 e aceito em 04/11/2020

\section{RESUMO}

A Geografia, enquanto disciplina escolar, é frequentemente observada pelos estudantes como uma área do conhecimento desinteressante e sem aplicabilidade concreta. Este trabalho tem o objetivo de apresentar as experiências didáticas realizadas no contexto do Estágio Supervisionado do curso de Licenciatura em Geografia da Universidade Estadual da Paraíba (UEPB), bem como ratificar a importância dessa etapa da formação para futuros professores. As atividades foram realizadas na Escola Cidadã Integral Assis Chateaubriand, localizada em Campina Grande-PB, contemplando uma turma do $2^{\circ}$ ano do ensino médio. Para tanto, os desdobramentos do estágio contaram com o estudo de textos referentes à formação inicial, à prática docente e ao uso de recursos multididáticos no ensino de Geografia, a fim de planejar atividades diferenciadas, contrárias ao massivo tradicionalismo persistente na educação e ampliando a visão sobre as abordagens geográficas no Ensino Médio. Como resultados, foi possível ratificar a importância do estágio supervisionado para formação docente e da diversificação dos recursos didáticos no ensino da Geografia no chão da escola, tendo em vista o aumento significativo do interesse dos estudantes pelas aulas. Também foi possível verificar um processo de ressignificação da presença do estagiário na escola, cuja aproximação entre a educação básica e a formação superior, beneficia também o professor regente e os discentes. A utilização de materiais considerados tradicionais também foi ressignificada, uma vez que o caráter cansativo se pauta na falta de dinâmica com o recurso, não no recurso didático em si.

Palavras-chave: Recursos multididáticos; Educação geográfica; Estágio supervisionado. 


\title{
MULTI-RESOURCES FOR GEOGRAPHIC EDUCATION IN HIGH SCHOOL: REFLECTIONS AND EXPERIENCES OF SUPERVISED INTERNSHIP
}

\begin{abstract}
Geography, as a school subject, is often seen by students as an area of uninteresting knowledge and without concrete applicability. This work aimed to present the didactic experiences carried out in the context of the Supervised Internship in Geography of the graduation course at Universidade Estadual da Paraíba (UEPB), as well as to ratify the importance of this stage of training for future teachers. The activities were carried out at Escola Cidadã Integral Assis Chateaubriand, located in Campina Grande-PB, contemplating a class from the $2^{\text {nd }}$ year of high school. For this purpose, the developments of the internship fell back on the study of texts related to initial training, teaching practice and the use of multidisciplinary resources in the teaching of Geography in order to plan differentiated activities, contrary to the massive persistent traditionalism in education and broadening the vision on geographic approaches in high school. As a result, it was possible to ratify the importance of the supervised internship for teacher training and the diversification of didactic resources in the teaching of Geography on the school floor, in the view of the significant increase in students' interest in classes. It was also possible to verify a process of reframing the presence of the trainee in the school, whose approximation between basic education and higher education, also benefits the conducting teacher and the students. The use of materials considered traditional has also been reframed, since the tiring character is based on the lack of dynamics with the resource, not on the didactic resource itself.

Keywords: Multidactic resources; Geographic education; Supervised internship.
\end{abstract}

\section{INTRODUÇÃO}

O ensino de Geografia é essencial para a construção da compreensão das relações entre o ser humano e o espaço onde este está inserido. No entanto, comumente essa disciplina não é indicada como uma das mais atraentes por muitos estudantes. De acordo com Castrogiovanni (2007), essa circunstância está relacionada ao excesso de práticas docentes pautadas no tradicionalismo desenvolvidas por muitos professores no decorrer das aulas e que, apesar dos desdobramentos históricos e dos consideráveis avanços no tocante ao ensino e à prática docente, ainda persistem nos espaços escolares fazendo com que os estudantes observem esta área do saber como apenas mais uma disciplina do currículo formal, de caráter descritivo, abstrato e sem muito a acrescentar em seu cotidiano.

Em um mundo ultradinâmico, equipado com frenéticas tecnologias constantemente superadas, que cada vez mais oferecem uma abundância de conteúdos atraentes, especialmente na internet, embora nem sempre produtivos, a continuação das práticas tradicionalistas na escola e a própria figura do professor, majoritariamente repetidor dessas práticas, não provoca nos estudantes o desenvolvimento do interesse pela 
utilização do espaço e do tempo na escola para a construção do conhecimento no exercício da reflexão crítica.

Transformar a percepção frequente e equivocada que os estudantes tem da Geografia enquanto uma "disciplina decorativa" e composta por textos expositivos e descritivos do espaço, para um olhar acerca desses conhecimentos, de modo que percebam a disciplina como uma área do saber comprometida com a explicação de fenômenos aparentemente sem importância direta para suas vidas, tem sido um dos principais desafios para os professores. Esse cenário evidencia a importância do desenvolvimento de estratégias mais dinâmicas e diferenciadas, que superem as práticas tradicionalistas ainda cotidianas no contexto educacional brasileiro, com o propósito de desenvolver o raciocínio geográfico e atrair o interesse dos discentes para a reflexão e compreensão dos fenômenos socioambientais.

Nos cursos de licenciatura, é fundamental que os futuros profissionais tenham contato com o cotidiano da escola ainda durante sua formação, não somente como um cumprimento da composição curricular desse processo formativo, conforme explicam Saiki e Godoi (2010), mas para o conhecimento da dinâmica real de seu futuro ambiente profissional, ao mesmo tempo em que têm a oportunidade de pensar no desenvolvimento de novas formas de ensinar Geografia.

Diante do exposto e considerando a relevância dos estágios para o processo de formação inicial de professores, esse trabalho tem como objetivo apresentar as experiências didáticas realizadas no contexto do Estágio Supervisionado em Geografia do curso de Licenciatura em Geografia da Universidade Estadual da Paraíba (UEPB/Campus Campina Grande), bem como ratificar a importância dessa etapa da formação para futuros professores. As atividades foram realizadas na Escola Cidadã Integral Assis Chateaubriand, localizada no bairro Santo Antônio, Campina Grande, contemplando uma turma do $2^{\circ}$ ano do ensino médio. O planejamento inicial foi realizado na universidade, de modo a identificar os possíveis problemas e construir soluções alternativas.

O trabalho está organizado de modo a discutir a importância do estágio supervisionado na formação docente em Geografia, seguida de uma reflexão a respeito da relevância do ensino de Geografia no Ensino Médio e do indispensável aperfeiçoamento da prática docente no processo ensino-aprendizagem. Posteriormente, é 
apresentado o diagnóstico da referida instituição de educação básica, pontuando-se as metodologias testadas e a realidade dos estudantes. Trata-se também do estágio supervisionado, desde a observação das aulas ministradas pelo professor regente até a fase da regência de aulas. Por fim, apresenta-se um projeto de intervenção pensado na ocasião do estágio e os resultados obtidos.

\title{
A importância do estágio supervisionado para a formação docente
}

Os estágios supervisionados representam a possibilidade de diálogo e construção contínua de conhecimentos entre os professores em formação inicial e o ambiente escolar, reforçando a necessidade de se considerar o ambiente coletivo e dinâmico que caracteriza a escola, bem como a importância do professor diante do contexto educativo. Trata-se da oportunidade que os futuros professores têm para compreender na prática sua real função social.

De acordo com Cavalcanti (2002, p. 110):

\begin{abstract}
A atuação do profissional exige uma formação que dê conta da construção e reconstrução dos conhecimentos geográficos fundamentais e de seu significado social, não basta o professor ter o domínio da matéria, é necessário tomar posições sobre as finalidades sociais da Geografia numa determinada proposta de trabalho, é preciso que o professor saiba pensar criticamente a realidade social e que se coloque como sujeito transformador dessa realidade.
\end{abstract}

Nesse sentido, um processo de formação inicial orientado para o exercício docente consciente é de extrema relevância para os desdobramentos do ensino dos conhecimentos geográficos no espaço escolar. É por meio das práticas de observação e regência que os graduandos podem depreender o significado da ação docente, através da qual suscitarão em seus futuros alunos o gosto pelo aprendizado dos conteúdos propostas pela disciplina, por interpretações socioespaciais concretas e consistentes, que tendem a acontecer mediante o papel fundamental de auxílio do professor.

A construção prática da docência tem seu início na universidade, a partir dos estágios supervisionados, que articulam teoria acadêmica, pesquisa acadêmica e escolar e prática docente nas escolas campo de estágio,

O conhecimento produzido na universidade, fundamentado em pesquisas de campo, bibliográfica, de laboratório e dominado pelo professor deve ser o instrumental teórico (matéria-prima) a ser elaborado, recriado para 
transformar-se em saber escolar, ou seja, em saber a ser ensinado (PONTUSCHKA, 1993, p. 203).

Coadunando com as perspectivas de Cavalcanti (2002), tão importante quanto o domínio dos conteúdos a serem abordados em sala de aula, é que o professor em formação desenvolva a habilidade de apresentá-los a seus alunos de maneira acessível, que pode ser adquirida durante a formação inicial nas disciplinas dedicadas às práticas de ensino.

A experiência do estágio é essencial na formação de qualquer profissional, não sendo diferente na formação docente, a qual se trata de uma oportunidade ao futuro professor de inserir-se no ambiente escolar não mais como estudante, mas como pesquisador e profissional que passa a perceber a escola como um ambiente de trabalho e experimentação das teorias tratadas no âmbito acadêmico, bem como o espaço próprio para a percepção real dos futuros desafios, além do aperfeiçoamento profissional prático.

O estágio trata-se do momento do processo formativo que viabiliza o início do delineamento profissional dos graduandos, tendo em vista que a partir do contato direto com o espaço escolar e com os professores supervisores da educação básica, é possível aos estudantes da graduação a troca de experiências e a reflexão acerca dos problemas e possibilidades sobre a realidade da profissão escolhida. Para Pimenta (2009), “[...] formadores e formandos encontram-se constantemente construindo identidades profissionais individuais e coletivas [...]”, sendo o espaço dedicado aos estágios a oportunidade de estabelecer as correlações entre teoria e prática.

A prática do ensino na educação básica é um exercício recorrentemente tido como intimidador aos estudantes das licenciaturas, seja pela insegurança natural dos futuros profissionais professores, pela conjuntura estrutural do sistema educacional brasileiro ou pela própria cultura, frequentemente rotuladora e disseminadora do imaginário de uma profissão árdua e desagradável, sustentando a imagem negativa e penosa do professor. Apesar dos constantes ataques à educação e à profissão de professor, é necessário fazer com que os graduandos se atentem para o espaço escolar enquanto um local de possibilidades de ação e de pesquisa, de modo que sejam desconstruídos possíveis olhares abstratos e sem significação acerca desse importante lócus formativo.

Nessa perspectiva, há de se considerar, nas últimas décadas, o reconhecimento da necessidade de transformação do papel ocupado pelos estagiários das licenciaturas. As discussões reforçam que os licenciandos devem aderir a uma prática reflexiva e ativa no 
contexto de realização dos estágios supervisionados tendo em vista que é fundamental que o futuro professor "[...] faça a reflexão sobre sua formação e sua ação e, dessa forma, possa aprofundar conhecimentos e compreender seu verdadeiro papel e o papel da escola na sociedade" (BARREIRO; GEBRAN, 2006, p. 90).

Os primeiros contatos com a prática docente não são simples e podem gerar desconforto ou até mesmo o abandono da formação. Contudo, o que muitos estudantes deixam de refletir é que o estágio se caracteriza como uma ferramenta singular de transformação do contexto educacional. Saiki e Godoi (2010) concordam que as práticas de ensino e o estágio supervisionado devam ser considerados como a instrumentalização fundamental no processo de formação profissional de professores, afirmando-os enquanto segmentos importantes na relação entre o trabalho acadêmico e a aplicação de teorias, além de articular os futuros profissionais com o espaço de trabalho, a sala de aula e as futuras relações.

Assim, a aproximação mais íntima ao exercício docente no próprio ambiente escolar proporciona ao estagiário a promoção da experiência aliada à ampliação do conhecimento específico e à confirmação (ou desacordo) dos estudos sobre as práticas docentes, que enriquecem e atualizam as discussões e possibilitam a descoberta de outros caminhos e modelos a serem refletidos, adaptados e aplicados por outros profissionais da educação.

\section{A relevância da educação geográfica no contexto do Ensino Médio}

O Ensino Médio compõe o ciclo final da educação básica, constituindo uma etapa que requer atenção especial principalmente devido a sua possibilidade norteadora dos próximos passos dos estudantes para suas formações acadêmicas em nível superior, e até mesmo no âmbito de sua inserção direta no mercado de trabalho. Independente da escolha ou não do subsequente caminho na academia, o momento da conclusão da formação básica naturalmente configura-se como reflexivo para o discente enquanto indivíduo social.

Nesse contexto, a Geografia é capaz de auxiliar o desenvolvimento da necessária compreensão acerca do papel social exercido por cada indivíduo, pois, como afirma Callai (2010), representa uma área do saber capaz de criar condições de auto reconhecimento 
para o aluno como sujeito ativo no espaço em que vive, possibilitando a compreensão dos fenômenos ocorridos como resultado da vida e do trabalho de construção da sociedade.

O professor de Geografia desempenha um papel fundamental, uma vez que cabe a este estimular a reflexão e o debate sobre os conteúdos ministrados, oportunizando ao aluno maior entendimento acerca das dinâmicas à sua volta, atribuindo maior significado à aprendizagem (ROSA, 2018). Saliente-se que, quando os conteúdos se encontram bem associadas aos fenômenos do contexto vivido, as abordagens, os conceitos e as reflexões alcançadas pelos estudantes do ensino médio através do pensamento geográfico, dão suporte ao desenvolvimento do pensamento crítico essencial nessa etapa da vida.

Para muitos, o ensino médio ainda é tido como um ciclo final da educação formal, o que o dota de uma importância ainda maior de uma abordagem geográfica mais completa, uma vez que muitos estudantes realmente não vêm a se submeter a nenhuma outra formação institucional na continuidade de suas vidas e, por motivos diversos, este pode ser o último contato com as reflexões tocantes à ciência geográfica.

De acordo com Barbosa et. al. (2017, p. 402),

[...] o ensino de Geografia no Ensino Médio procura concretizar os conteúdos de aprendizagem que foram explanados no Ensino Fundamental, formando cidadãos capacitados para compreender a importância da apropriação do espaço em suas diferentes escalas, levando em consideração os aspectos social, técnico, político e ambiental.

Dessa maneira, tendo em vista a importância dessa etapa da educação básica para a formação dos estudantes, a disciplina de Geografia reforça a relevância de um aprendizado concreto e articulado à realidade. Para a maioria dos estudantes que anseiam a formação de nível superior, o ensino médio é o último momento da formação básica para a aquisição de conhecimentos e habilidades necessárias para os futuros exames de ingresso nas instituições superiores, como provas de vestibulares e o Exame Nacional do Ensino Médio - ENEM, principal exame de entrada para a maioria das instituições públicas e privadas do país. Tais exames, apesar de multidisciplinares, são frequentemente pensados, preparados e direcionados a fenômenos do campo social, considerando a interação entre a natureza e sociedade, cujo objeto é o fundamento de análise da ciência geográfica.

O Exame Nacional do Ensino Médio foi proposto pelo Instituto Nacional de Estudos e Pesquisas Educacionais Anísio Teixeira (Inep), havendo sido realizada sua 
primeira edição no ano de 1998, com a finalidade de avaliar os estudantes ao final da educação básica. Entretanto, no ano de 2009, esse exame recebeu uma nova reformulação e assumiu uma nova proposta de avaliação e aprendizagem, pautada e fundamentada nas Orientações Curriculares Nacionais e nos Parâmetros Curriculares Nacionais para o ensino médio, os "PCNs".

No campo das ações públicas para a educação, o ENEM se configura, conforme Hollas e Bernard (2020, p. 111), como uma importante ferramenta de avaliação do ensino básico. Ainda segundo os autores, podemos afirmar que:

\begin{abstract}
Além de avaliar os estudantes que concluem o ensino médio, tal exame instalase como uma ferramenta para o estabelecimento de índices de qualidade da educação básica e contribui com a efetivação, ou não, de políticas educacionais. Em outro aspecto também pode ser considerado um processo seletivo para o ingresso na Educação Superior, e, por isso, influencia a mobilização por mudanças nos processos educativos do ensino médio no intuito de preparar os estudantes para a prova.
\end{abstract}

De acordo com as orientações do currículo de Geografia para o Ensino Médio, essa ciência deve preparar os discentes para "localizar, compreender e atuar no mundo complexo, problematizar a realidade, formular proposições, reconhecer as dinâmicas existentes no espaço geográfico, pensar e atuar criticamente em sua realidade tendo em vista a sua transformação" com o objetivo que os discentes compreendam a dinâmica socioespacial que reproduz o espaço em diferentes escalas, seja da local à global (BRASIL, 2006, p. 43).

Entretanto, a grande polêmica em torno dos conteúdos de Geografia no ENEM está atrelada à questão da abordagem não regional, ou seja, se encaminha um processo de aprendizagem sobre conteúdos diversos da disciplina, como se estes não mantivessem relação com o espaço vivido pelo estudante. Dessa maneira, determinados espaços são supervalorizados nas análises geográficas, em distintas escalas, impossibilitando ao estudante desenvolver um olhar atento ao seu lugar e estabelecer as conexões necessárias para realizar, de forma autônoma, uma análise consciente e crítica acerca das dinâmicas do seu lugar. Conforme aponta Rocha (2014, p. 26-27):

Pensar geograficamente na prova do ENEM exclui escalas espaciais importantíssimas para o pensamento geográfico escolar, contrariando, inclusive, outros documentos oficiais como as Orientações Curriculares para o Ensino Médio (MEC, 2006) que, por sua vez, favorecem a leitura e análise de 
escalas cotidianas para o aprendizado geográfico. Como exemplo da valorização da escala cotidiana.

Logo, apesar dos constantes ataques ao ensino de Geografia no Ensino Médio, constatados através das transformações promovidas pela Lei no $13.415 / 2017$, que não insere claramente as disciplinas de História e Geografia como obrigatórias no currículo, a perspectiva crítica que permeia a disciplina faz dela um elemento de relevante importância para a formação de sujeitos críticos e capazes de estabelecer um raciocínio geográfico lógico e autônomo. Todavia, ainda são perceptíveis práticas que priorizam entre os estudantes a compreensão dos conteúdos como se fossem algo distante de sua realidade, fato este que pode ser relacionado não apenas a existência de práticas tradicionais que se cristalizaram na ação docente e no espaço escolar ao longo do tempo, como também das perspectivas que gravitam sobre exames aplicados à esses estudantes e que valorizam determinados espaços do país e do mundo, como é o caso do ENEM.

Ademais, deste cenário decorre a premência do uso de estratégias didáticas que auxiliem na compreensão dos conteúdos de Geografia, de modo a retirar-lhes a abstração, ou o distanciamento com o qual muitos estudantes ainda o percebem desenvolvendo neles a habilidade de transitar entre as escalas de análise sem maiores problemas, no tocante ao encadeamento lógico existente nos fenômenos socioespaciais, que, de alguma forma, são refletidos pelos múltiplos espaços existentes.

\section{Estratégias didáticas no processo ensino-aprendizagem}

A necessidade de o professor acrescentar em seu trabalho docente estratégias didáticas, capazes de despertar o interesse dos estudantes pelo aprendizado, constitui-se como uma das pautas mais discutidas no âmbito da educação e da prática de professores. Nesse sentido, um dos pontos nevrálgicos do processo de formação, seja inicial ou continuada, diz respeito à efetivação de uma relação satisfatória entre os campos da teoria e da prática durante a formação e a ação profissional, bem como da internalização de uma prática reflexiva.

O constante aperfeiçoamento da prática docente é uma atitude necessária, tendo em vista a importância de que o professor acompanhe as transformações da sociedade para que possa realizar um trabalho consistente e significativo junto a seus alunos. Logo, o processo ensino-aprendizagem depende da sistemática social e vice-versa. 
Conforme Silva e Leite (2019), a formação continuada na disciplina de Geografia é de extrema importância no desenvolver da prática docente, pois essa atividade permite aos professores refletir e aperfeiçoar suas práticas em sala, contribuindo para que possam se adequar às mudanças no que diz respeito ao relacionamento com os alunos e ao uso de recursos didáticos.

As transformações sociais e o frenético ritmo tecnológico presentes condicionam o acesso a instrumentos que, apesar de possuírem um potencial agregador para o processo de aprendizagem, podem representar um instrumento de distração para os estudantes que, em sua maioria, não utilizam a tecnologia para fins de estudo. Este fato suscita a reflexão acerca do uso adequado pelos professores de estratégias didáticas capazes de transformar esse cenário.

$\mathrm{Na}$ era informacional, a maneira de agir e pensar mudam de forma extraordinária, essa alteração repercute no comportamento a assimilação das informações do conhecimento. Frente a esta situação, os docentes devem se abrir para diferentes formas de Educação (ANDRADE, 2020). A utilização adequada de novas tecnologias em sala de aula, tendo como ponto de partida um planejamento cuidadoso e com objetivos claros para a aprendizagem, é capaz de atribuir maior significado aos conteúdos propostos, favorecendo a interação dos alunos.

De acordo com Nascimento (2020, p. 6):

\begin{abstract}
Existem inúmeros recursos tecnológicos que podem facilitar o processo de aprendizagem do ensino da geografia. O computador, o principal produto das tecnologias de comunicação, ganha destaque e importância neste quesito. Rico em recursos audiovisuais possibilita o entrecruzamento de imagens, sons e textos. Os Atlas digitais, por exemplo, estão sendo muito utilizados na educação geográfica, assim como diversos software educativo de apoio aos conteúdos curriculares, de jogos e simulações para o ensino de Geografia que podem estimular os alunos na aprendizagem dessa disciplina.
\end{abstract}

No entanto, a grande dificuldade enfrentada nas escolas de rede pública, para utilização de novas tecnologias no ensino de Geografia está atrelada à falta de investimentos. Com isso, o uso de equipamentos tecnológicos enfrenta problemas desde a falta de infraestrutura física da escola, até a falta de capacitação dos professores para o uso destes equipamentos (FREITAS et. al., 2020).

Cabe aqui destacar que a adoção de metodologias didáticas, consideradas tradicionais no ambiente escolar, não caracterizam, por si sós, uma prática ultrapassada. 
Entretanto, a forma como tais práticas são executadas pode provocar a perpetuação do desinteresse generalizado nas aulas. Diversas estratégias podem ser adotadas para transformar a percepção discente acerca da escola enquanto um espaço maçante, de conteúdo desinteressante e da educação indiferente.

Entre as estratégias que podem ser utilizadas em sala para despertar o interesse dos alunos, estão a utilização de jogos, construção de maquetes, leitura e análise de figuras e imagens, aulas práticas com experiências em sala de aula, aulas de campo, entre outros procedimentos metodológicos dinâmicos, que aumentam assimilação do ensino geográfico por parte do discente.

\section{METODOLOGIA}

\section{O chão da escola: campo prático do estágio supervisionado}

A Escola Cidadã Integral Assis Chateaubriand funciona na Rua Alice Galdêncio, 2500, em um ponto adjacente entre os bairros Santo Antônio, Castelo Branco e Monte Castelo, situados na Zona Leste da cidade Campina Grande, no Estado da Paraíba, Brasil (Figura 1).

Desde o primeiro bimestre do ano de 2018, o Governo do Estado adotou para a instituição o modelo de ensino denominado Escola Cidadã Integral (ECI), definido por meio da medida provisória $n^{\circ}$ 267, de autoria do Poder Executivo (PARAÍBA, 2018).

Figura 1 - Localização da Escola Cidadã Integral Assis Chateaubriand.

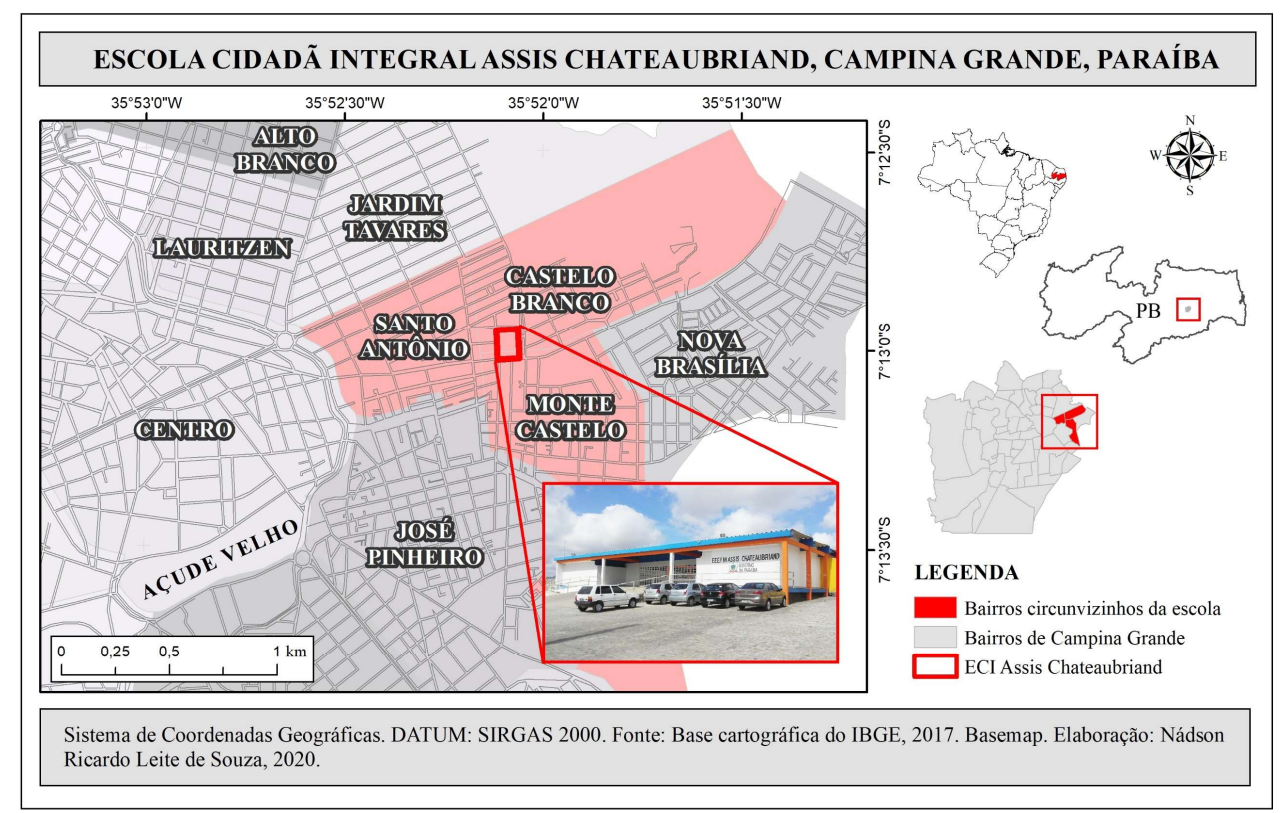

Fonte: Composição autoral, 2020. 
O modelo Escola Cidadã Integral determina um regime de dedicação integral não só para os estudantes, mas também para os docentes que cumprem carga horária de 40 horas semanais, sendo 28 horas em sala de aula e o restante a fim de ser dedicado aos estudos, em práticas de planejamento, atendimento ao público no âmbito escolar ou atividades extras, como projetos multidisciplinares.

O modelo de ECI resulta de políticas públicas inseridas no Plano Nacional de Educação, que objetivam alcançar no mínimo 50\% das escolas públicas (PARAÍBA, 2018). A nove aulas diárias oferecidas na instituição ocorrem entre das $07 \mathrm{~h} 30$ às $17 \mathrm{~h}$, com intervalos destinados às refeições, sendo 20 minutos para o lanche da manhã, o almoço, que começa a ser servido a partir do meio dia e o lanche da tarde, servido às $15 \mathrm{~h}$.

\section{PERCURSO METODOLÓGICO}

O planejamento do estágio supervisionado ocorreu em dois momentos distintos, que contaram, inicialmente, com reflexões sobre as temáticas referentes ao ensino de Geografia, à formação de professores e uso de recursos alternativos ao livro didático. A primeira parte ocorreu ainda na universidade, onde foram discutidos textos de alguns autores como Melo (2010), Saiki \& Godoi (2010) e Silva e Melo (2016), que discutem a importância do estágio, as práticas de ensino em Geografia e as experiências em sala de aula.

A segunda parte ocorreu na escola, onde foram identificadas as características da turma do $2^{\circ}$ ano do ensino médio e planejadas atividades de intervenção a partir das principais necessidades identificadas. Esta etapa foi realizada nas duas semanas iniciais do período do estágio, em agosto de 2019.

Para o início das atividades do estágio supervisionado em sala de aula, foi pensada a realização de uma atividade de socialização entre os doze alunos do $2^{\circ}$ ano do ensino médio e o professor estagiário. O objetivo da atividade de socialização foi estreitar a relações e tornar o ambiente da sala de aula descontraído, para que depois fosse aplicado um questionário diagnóstico, de caráter anônimo, para conhecimento das características pessoais, socioeconômicas da turma, como as idades, o local onde moravam, a profissão dos pais ou responsáveis e o tempo em que cada um estudava nessa instituição. Nesse 
questionário, eles também puderam expressar sua opinião a respeito das metodologias empregadas pelo professor regente, das atividades realizadas, das avaliações e apresentar sugestões de melhoria no ensino de Geografia.

O questionário aplicado ainda buscou alcançar a percepção da turma a respeito do objetivo e da importância de se estudar Geografia. A partir dos resultados obtidos na pesquisa, foram planejadas estratégias de intervenção a serem executadas no decorrer das aulas, a fim de dinamizá-las, por meio de atividades lúdicas, com a utilização de recursos múltiplos e uma possível aula de campo, onde os estudantes pudessem aproximar-se de seu objeto de estudo.

De forma a dinamizar o conteúdo programático a ser apresentado durante o Estágio Supervisionado, foram adotadas as propostas de Silva e Melo (2016), Oliveira (2009), Melo (2010) e Saiki \& Godoi (2010), tais autoras defendem o uso de recursos didáticos enquanto alternativas para dinamizar as aulas e acrescentar maior significado aos conteúdos e à prática docente. Ainda segundo as autoras, atividades lúdicas simples e acessíveis, como jogos e desafios confeccionados de acordo com os temas estudados, contribuem para o processo ensino-aprendizagem como sintetizadores das principais habilidades que os alunos deverão adquirir a respeito do conteúdo estudado.

\section{RESULTADOS E DISCUSSÕES}

\section{Diagnóstico da turma: análise dos questionários aplicados}

O desenvolvimento das práticas de estágio supervisionado ocorreu em uma turma com doze estudantes do $2^{\circ}$ ano do Ensino Médio, sendo sete do gênero feminino e cinco do gênero masculino. A maior parte dos estudantes possuía 16 anos de idade, havendo dois alunos com 15 anos e um com 17 anos. Todos estudavam na instituição há pelo menos seis anos, sendo a totalidade da turma residente no mesmo bairro onde está situada a escola ou nos bairros circunvizinhos, já representados no mapa 1 .

A partir do questionário aplicado, foi constatado ainda que a maior parte dos responsáveis se enquadrou na profissão "agricultor” ou está atualmente desempregada. Apenas um aluno afirmou que o responsável possui curso superior. 
A respeito da opinião da turma sobre a identificação com as metodologias utilizadas pelo professor nas aulas e a importância da disciplina de Geografia no dia a dia, foi averiguado que a maioria dos estudantes da turma se identifica bastante com a disciplina, mas consideraram as aulas cansativas (58\% das respostas, ver figura 2), citando como motivação o excesso de práticas tradicionalistas, como "escrever demais" e "fazer exercícios o tempo todo [se referiram aos questionários de fixação de conteúdo escritos, realizados tanto no horário da aula, quanto como atividade para casa]".

Saliente-se que, uma postura tradicional nem sempre está relacionada ao uso de recursos didáticos considerados tradicionais, mas sim como estes são utilizados pelo docente durante suas aulas, um ótimo exemplo é o uso do livro didático. Indiscutivelmente, ele é o recurso mais acessível aos alunos, ainda que não houvesse livros suficientes para todos no caso apresentado, entretanto, é comumente tido como um instrumento extremamente tradicional pelo seu formato e pelas perspectivas de uso atribuídas pelos docentes a este recurso, cabendo ao professor desmistificar essa ótica equivocada, a partir de uma prática que valorize os elementos do livro didático e permita o diálogo entre professor e alunos.

Ao provocar os estudantes a partir de imagens, mapas, gráficos e tantos outros elementos contidos no livro didático, o professor já estará desenvolvendo uma prática que supera o tão discutido e criticado "excesso de tradicionalismo". Em contra partida, caso esse mesmo professor desenvolva sua aula a partir da exposição do conteúdo em slides, a partir de filmes ou documentários de forma unicamente expositiva, sem espaço para o diálogo e reflexão junto a seus alunos, estará retomando ao tradicionalismo, mesmo fazendo uso de recursos considerados não-convencionais. Nesse sentido, o feedback dos estudantes no decorrer (e após) a abordagem do conteúdo é fundamental para identificar quais os direcionamentos das práticas que vem sendo realizadas.

Muitas vezes, a inquietação dos estudantes em relação ao tradicionalismo que observam e criticam nas aulas pode ser explicada através da ausência do planejamento das atividades por parte do professor. Segundo Libâneo (1994), o planejamento constituise enquanto etapa fundamental para que sejam obtidos resultados positivos no processo ensino-aprendizagem, uma vez que a partir da reflexão e da organização, o professor pode encaminhar os desdobramentos de sua aula, de modo a superar as perspectivas tradicionalistas no tocante ao uso de certos recursos didáticos. 
Durante o encaminhamento das atividades de estágio, foi possível estabelecer uma relação de troca e construção de conhecimentos entre estagiário e professor regente, tendo em vista que este mostrou-se aberto ao diálogo e às propostas do professor estagiário, uma vez que alguns alunos indicaram o tradicionalismo como um dos entraves recorrentes nas aulas de Geografia, os professores buscaram juntos superar essa dificuldade. Dessa forma, o planejamento conjunto das aulas ampliou as visões de ambos no que concerne à inovação metodológica, sob a perspectiva do uso de multirecursos, confirmando a importância da presença do estagiário no espaço escolar, cuja relação obviamente proporciona melhorias no processo ensino-aprendizagem e aproxima o público discente da universidade.

Quando questionada sobre suas percepções acerca da Geografia como disciplina escolar, a maioria da turma considerou os estudos da ciência geográfica como sendo de fundamental importância no dia a dia e uma minoria considerou esses conhecimentos indiferentes, mas nenhum dos alunos alegou que essa disciplina não tem importância. Os gráficos da Figura 2 expressam os percentuais relacionados às respostas dos alunos.

Figura 2 - Gráficos representando a opinião dos estudantes a respeito o interesse pessoal em estudar a disciplina Geografia e a importância em seu dia a dia.

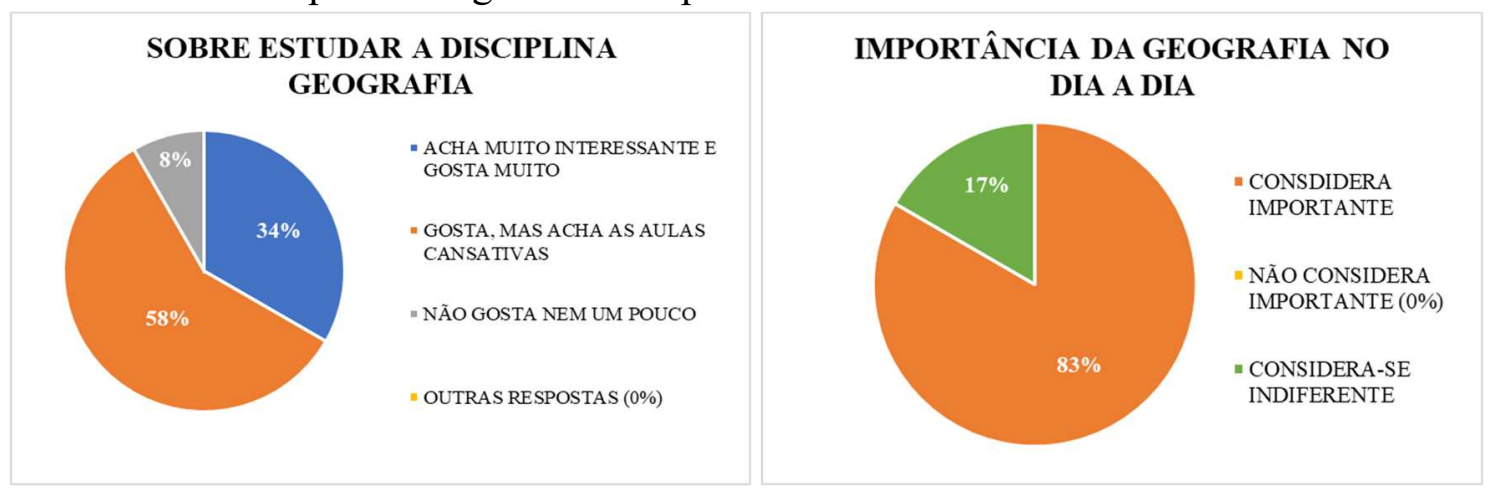

Fonte: Os autores, 2020.

Do total dos estudantes da turma, 58\% relataram gostar da disciplina. Todavia, afirmaram achar as aulas de Geografia enfadonhas, explicando que isso ocorria em consequência da quantidade e da frequência de textos que eram obrigados a escrever no caderno, além das atividades de pergunta e resposta (dissertativas) que eram solicitadas. Segundo os relatos, essas metodologias eram frequentes e não os auxiliavam tanto para a construção do conhecimento crítico e reflexivo. Assim, compreende-se a importância do 
reconhecimento do espaço da sala de aula como um local de diálogo, interação e construção de conhecimentos significativos.

Ainda sobre o questionário aplicado, 34\% responderam que gostam muito da disciplina e acham muito interessante os conhecimentos adquiridos durante as aulas, mostrando que os conteúdos geográficos já são percebidos por muitos alunos como algo que faz parte de sua realidade. Apenas $8 \%$ dos alunos alegaram não se identificar nem um pouco com a disciplina de Geografia.

Quando perguntados sobre a importância da disciplina entre as disciplinas escolares, $83 \%$ afirmaram considerar importante os conhecimentos da área. Os discentes mostraram durante as aulas que compreendem as relações entre a Geografia e seu cotidiano, por essa razão enxergam a importância da disciplina em questões simples como localização, orientação, entendimento das dinâmicas urbanas, entre outros assuntos. Os 17\% restantes permanecem afirmando que não há importância alguma na disciplina, e que ela é apenas mais uma do currículo para a qual devem estudar e "tirar notas boas", não havendo aplicabilidade dos conhecimentos geográficos para este grupo de alunos.

Sobre o nível de dificuldade enfrentado ao estudar os conteúdos da disciplina Geografia, a maioria dos estudantes da turma considerou mediano, seguido dos que consideraram fácil. A menor parcela de alunos da turma considerou difícil. O gráfico da Figura 3 expressa o percentual relacionado às suas opiniões.

Figura 3 - Opinião dos alunos a respeito da dificuldade em estudar Geografia

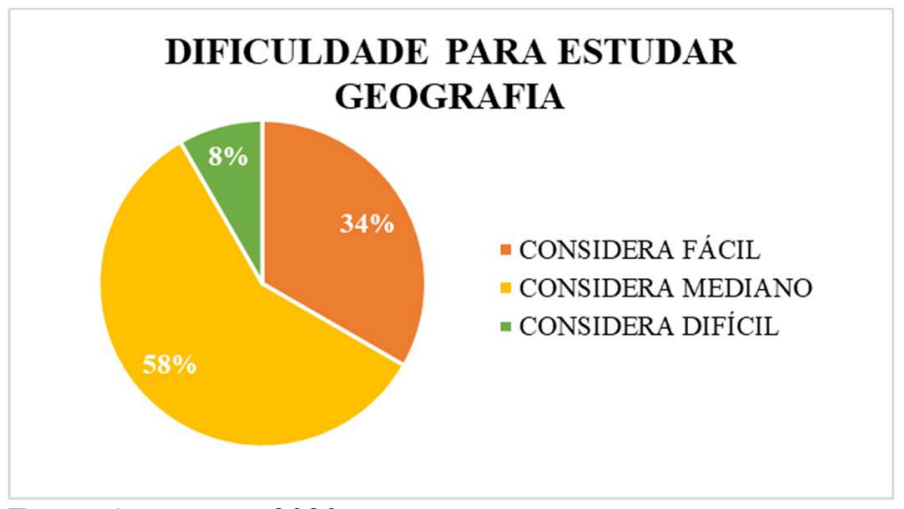

Fonte: Os autores, 2020.

A turma em questão, embora tenha demonstrado interesse pela disciplina Geografia e reconhecimento a respeito de sua importância e objeto de estudo, confirmou 
o descontentamento com as excessivas práticas tradicionalistas presentes no cerne das metodologias de ensino de Geografia da educação básica brasileira.

Durante a observação das aulas do professor regente e ao longo da realização da regência de estágio supervisionado, não foram constatados na turma problemas que comprometessem sua concretização. Felizmente, em virtude da quantidade de alunos, pôde-se focar nas necessidades de cada aluno com mais proximidade, fato que viabilizou o desenvolvimento das atividades de maneira a atender suas sugestões. Apesar da baixa quantidade de alunos ser positiva em alguns aspectos, averiguou-se que essa característica não ocorre ao acaso.

Em virtude de a escola atender bairros populares da cidade de Campina Grande e de a maioria dos alunos da turma pertencerem a núcleos familiares os quais são providos por responsáveis cujas atividades profissionais não aparentam ser bem remuneradas, muitos dos alunos da localidade necessitam ingressar precocemente em atividades remuneradas para contribuir com a renda do núcleo familiar.

A suposição aqui descrita a respeito de tal característica foi confirmada diversas vezes, quando os próprios alunos, em conversas aleatórias entre si, citaram ex-colegas de classe que foram obrigados a afastar-se do modelo de Escola Cidadã Integral ou mesmo de alguns deles que já demonstraram-se determinados a sair da escola em questão, em virtude da necessidade de trabalhar em algum dos turnos. Dessa forma, acreditamos que tal característica justifica a evasão averiguada na turma do segundo ano.

A turma foi questionada ainda a respeito dos planos futuros de ingresso na educação superior, informação considerada relevante, uma vez que, em sua faixa etária, se considera comum que tais planos já tenham sido ou venham sendo pensados pelos estudantes desta série. A maioria deles afirmou o interesse em realizar algum curso superior, outros afirmaram o interesse em seguir carreira militar ou autônoma.

\section{Estratégias didáticas e atividades desenvolvidas no estágio supervisionado}

O conteúdo programático trabalhado em sala de aula pelo professor estagiário seguiu o planejamento do professor regente, coincidentemente planejado para ser iniciado no mesmo dia em que o professor estagiário estaria iniciando suas atividades. Sobre o tema, tratava-se de "Indústria Brasileira", dentro do qual deveriam ser abordados os 
processos históricos da industrialização mundial, os tipos de indústria, a indústria no Brasil e os impactos ambientais decorrentes desta atividade.

O material disponibilizado pela escola foi o livro didático "Geografia no cotidiano", do 2ªno, produzido no ano de 2016 por Dadá Martins, Francisco Bigotto e Márcio Vitiello e publicado pela Base Editorial. Constatou-se que não havia livros didáticos na escola em quantidade suficiente para todos os alunos, mesmo com o pequeno número de alunos na turma em questão. Foi observado que o material trata de assuntos bastante complexos a respeito da Indústria, contudo, de modo bastante resumido e sem apresentar exemplos próximos da realidade dos alunos. O livro didático foi utilizado, contudo, outros materiais foram adotados, os quais serão detalhados mais adiante.

No segundo encontro, onde as aulas foram iniciadas com o conteúdo, optou-se por não utilizar o livro didático como recurso, mas abordar o tema a partir da noção já adquirida pelos alunos a respeito do assunto. No mesmo encontro foi realizada uma revisão oral a respeito da Geografia e das categorias de análise espacial, na qual averiguou-se que os alunos já haviam estudado tais temas em anos anteriores, mas somente alguns puderam definir as categorias com maior aproximação ao seu conceito.

A abordagem inicial realizada a respeito do tema "Indústria" foi executada de modo a considerar os diversos processos históricos que levaram ao desenvolvimento industrial na Inglaterra até chegar à presença e evolução da indústria na cidade de Campina Grande. Para tal, foi utilizada uma charge e algumas fotografias desse momento histórico local, dispostos na figura 4.

Figura 4 - Charge e fotografias utilizadas como recurso didático nas aulas.
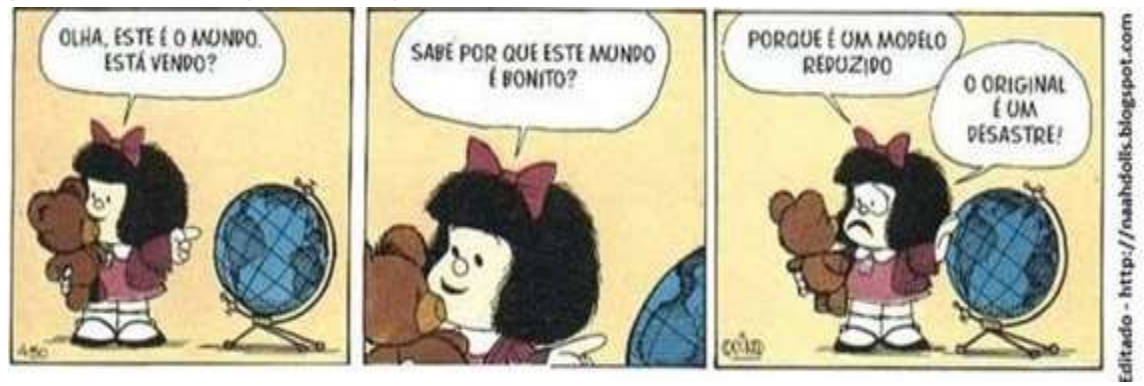


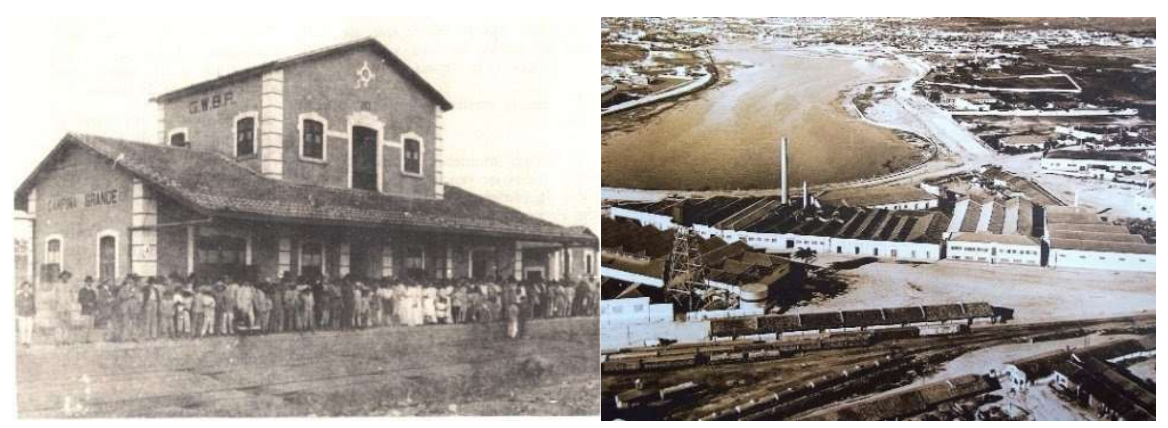

Fonte: Geonauta, 2019 / Estações, 2019.

Em continuidade à abordagem sobre o conceito de "Indústria", duas aulas foram destinadas à exibição de alguns vídeos curtos, produzidos e ambientados em diferentes espaços e períodos, mas que em seu cerne traziam fatos relacionados ao tema estudado. O Quadro 01 apresenta os recursos multimídia utilizados durante as aulas:

Quadro 1 - Material multimídia utilizado como recurso didático durante as aulas.

\begin{tabular}{|c|c|c|}
\hline FILME/VÍDEO & DURAÇÃO & DESCRIÇÃO \\
\hline $\begin{array}{c}\text { Modern Times* } \\
\text { (Tempos Modernos) }\end{array}$ & $1 \mathrm{~h} 29 \mathrm{~m}$ & $\begin{array}{l}\text { Produzido em 1936, o clássico longa- } \\
\text { metragem dirigido por Charles Chaplin, } \\
\text { ilustra a dinâmica industrial da época ao } \\
\text { trazer uma crítica ao modelo de produção } \\
\text { capitalista e às precárias condições de } \\
\text { trabalho instauradas desde a Primeira } \\
\text { Revolução Industrial. }\end{array}$ \\
\hline $\begin{array}{l}\text { The Story of Stuff } \\
\text { (A História das Coisas) }\end{array}$ & 21 minutos & $\begin{array}{l}\text { Produzido em 2007, o curta-metragem } \\
\text { dirigido por Louis Fox, aborda a trajetória } \\
\text { da construção social pautada na crítica ao } \\
\text { sistema de produção capitalista abusivo e } \\
\text { incentivador do consumo desenfreado. }\end{array}$ \\
\hline Ilha das Flores & 13 minutos & $\begin{array}{l}\text { Produzido em 1989, o curta-metragem } \\
\text { brasileiro (tipo documentário), dirigido por } \\
\text { Jorge Furtado, explica a desigualdade } \\
\text { gerada pelo sistema econômico vigente a } \\
\text { partir de uma conscientização social ao } \\
\text { mostrar um exemplo real e desumano nas } \\
\text { relações criada pelo sistema de consumo. }\end{array}$ \\
\hline A falta que a falta faz & 9 minutos & $\begin{array}{l}\text { Vídeo do canal "JoutJout Prazer", no } \\
\text { YouTube, no qual a vloger lê um livro } \\
\text { intitulado "A parte que falta", de Shel } \\
\text { Silverstein (1976), tratando da sensação da } \\
\text { "falta" do que não se tem. }\end{array}$ \\
\hline
\end{tabular}

Fonte: Organização autoral, 2020.

*Do filme "Tempos Modernos" foram exibidos apenas os primeiros 19 minutos, julgados como suficientes para abordar a temática da aula, tendo em vista o planejamento da aula. 
A proposta da exibição dos filmes foi pautada na ampliação e no enriquecimento da discussão sobre o consumo também em diversas perspectivas, desde a do consumo de produtos relacionados à produção industrial em massa até a perspectiva dos relacionamentos, que também são transformados em mercadoria na esfera capitalista.

Com a exibição dos filmes e a realização das discussões reflexivas entre o professor estagiário e o aluno, foi proposta a construção de uma "Nuvem de palavras", para assimilação dos diversos tipos de indústria a partir de palavras-chave retiradas do livro didático. Os estudantes falavam as palavras, que eram escritas no quadro pelo estagiário e posteriormente todas essas palavras foram objeto de discussão e os alunos foram incentivados a relacioná-las às fotografias impressas, levadas pelo professor estagiário, que ilustravam os diversos tipos de indústria.

Essa mesma experiência pedagógica foi realizada por Prais e Rosa (2017), quando no contexto de um curso de extensão para formação de professores no Paraná, as pesquisadoras identificaram o grande potencial dessa estratégia. No caso apresentado por elas foi utilizado um programa específico, o wordle, facilitando e conferindo um ar mais tecnológico à atividade, mas ratificando o que foi observar também com a turma de ensino básico objeto deste estudo.

Após a abordagem do tema em questão, foi elaborada uma atividade com questões objetivas retiradas de provas de vestibulares diversos, incluindo questões do ENEM. Com essa prática objetivou-se aproximar os alunos do modelo de questões de vestibular, nas quais os alunos demonstraram-se motivados a resolvê-las. Diante do êxito da atividade, o professor regente decidiu atribuir uma das notas do bimestre a partir do resultado dessa atividade.

O projeto de intervenção pensado para a turma do $2^{\circ}$ ano "A", em conjunto com os professores supervisores, focava a ideia de realizar uma aula de campo, uma vez que tanto o tema estudado quanto a pontos específicos, como o Museu do Algodão e o Museu do Sesquicentenário (SESI), da cidade onde se situa a escola favoreciam uma rica prática e reflexão, além de trazer o "dinamismo", correntemente sugerido pelos alunos. A instituição, contudo, esteve enfrentando um problema em sua administração durante quase todo o período do estágio inviabilizando a efetivação da proposta, que não chegou a ser compartilhada entre os alunos. 
Ocorreu que dois gestores assumiram o cargo e solicitaram exoneração, logo em seguida. Dessa forma, a escola esteve enfrentando problemas financeiros, segundo relatado, que inviabilizou, dentre tantos serviços, a compra de gás, o consequente não funcionamento da cozinha e a redução forçada na carga horária das aulas. A turma em si não apresentou problemas que comprometessem a execução do planejamento das aulas, mas os problemas administrativos da escola impossibilitaram a realização da aula de campo, cuja visita em grupo chegou a ser reagendada e desmarcada por três vezes consecutivas no Museu do Sesquicentenário (SESI), situado a cerca de 2,5 quilômetros da instituição.

Apesar dos problemas enfrentados pela escola, com carga horária reduzida, as aulas ocorreram de forma bastante satisfatória, nas quais foi possível cumprir o planejamento de forma completa, excetuando-se apenas a aula de campo pelas razões já apresentadas. Ao final, a turma aparentava haver ampliado a criticidade de seu olhar sobre os fenômenos e objetos produto da industrialização.

\section{CONSIDERAÇÕES FINAIS}

As vivências durante o estágio supervisionado podem ser consideradas como uma etapa imprescindível na formação docente em Geografia, que ressignificam a relação entre os espaços escolar e universitário sob a perspectiva da formação docente, da pesquisa e da inovação metodológica, uma vez que o chão da escola e suas dinâmicas oportunizam múltiplas descobertas acerca da profissão desvendando-a, enfatizando as necessidades formativas e inovando as práticas do exercício docente, capazes de fomentar o desenvolvimento reflexivo e crítico dos discentes, bem como incentivando sua criatividade.

As atividades desenvolvidas mostraram que a aplicação de metodologias diversificadas foi eficiente, uma vez que todas as atividades planejadas foram facilmente acolhidas pelos alunos e também pelo professor regente, que sempre aparentavam encarar como desafios e não como meras obrigações. Sabe-se, contudo, que em virtude do dia a dia docente não é possível ou sugerida a extinção daqueles recursos considerados símbolos das práticas tradicionais nas escolas, como o quadro branco, pincel e carteiras enfileiradas. 
Nesse sentido, depreende-se que a atividade docente exige uma mescla de recursos, aqui considerando-se que os impasses verificados gravitam sobre a ausência de planejamento, o uso excessivo de práticas tidas como tradicionais, e a resistência com relação a mudanças no desenvolver do trabalho docente. Destaque-se que, o tradicionalismo reside muito mais nas formas de uso dos recursos didáticos do que na utilização deles em si, fazendo com que o processo ensino-aprendizagem requeira inovações que dialoguem com o contexto do cotidiano escolar, sendo desenvolvido de forma dinâmica e associada ao objetivo comum de uma educação crítica, especialmente em Geografia.

A interdisciplinaridade cada vez mais acentuada e desenvolvida na escola, e em conjunto com outros professores, pode trazer benefícios aos discentes, como foi constatado na turma objeto desta pesquisa, especialmente referindo-se à disciplina de Geografia, que atua como uma das ciências mais interdisciplinares que existem e, ao contrário do recorrente isolamento da disciplina no contexto sistemático da educação básica, esta necessita de maior integração a outras disciplinas e com o contexto espacial, temporal e fenomenológico no qual os alunos se inserem.

Como disciplina obrigatória dos cursos de Licenciatura em Geografia, o estágio supervisionado em Geografia é capaz de oportunizar a experiência docente no campo da teoria e da prática: a escola. As dificuldades da profissão, os entraves cotidianos e as questões estruturais do sistema educativo brasileiro fazem-se presentes durante a realização do estágio, mas oferecem a possibilidade de contornar os imprevistos e buscar maneiras distintas de fazer acontecer o ensino de Geografia.

Faz-se necessário enfatizar que a formação para a docência é um caminho a ser percorrido por todo o tempo de exercício da profissão. Nesse sentido, deve-se atentar para a importante relação entre os espaços acadêmicos e escolares, ambos como locais de pesquisa, a partir dos quais são construídas reflexões relevantes, capazes de proporcionar possibilidades de avanço e aprimoramento da formação docente, seja ela inicial ou continuada. Logo, considerar os estágios supervisionados sob as perspectivas de (re) construção de teorias e práticas relativas à docência, bem como espaços profícuos de troca e interação representa um caminho para alcançarmos as transformações tão almejadas no tocante ao ensino de Geografia nos espaços escolares. 


\section{REFERÊNCIAS}

A FAlTA QUE A FALTA FAZ. Canal "JoutJout Prazer", YouTube. (8 min.) Disponível em: $<$ https://www.youtube.com/watch?v=GFuNTV-hi9M $>$. Acesso em: 26 de set. de 2019, às $19 \mathrm{~h} 39 \mathrm{~min}$.

ANDRADE, Fernanda Machado. As influências das novas tecnologias no ensino da Geografia. In: Revista Eletrônica Educação geográfica em Foco, ano 4, n ${ }^{\circ}$ 7, Especial $2^{\circ}$ ELG, abril de 2020. Disponível em: http://periodicos.pucrio.br/index.php/revistaeducacaogeograficaemfoco/article/view/986/715. Acesso em: 06 outubro 2020.

BARBOSA, A. C.; SILVA. J. S. e. O conhecimento local em face do ENEM: as implicações do ensino de Geografia. In.: Revista Brasileira de Educação em Geografia, Campinas, v. 7, n. 13, jan/jun 2017 (400-416).

BARREIRO, I. M. de F; GEBRAN, R. A. Prática de Ensino e Estágio Supervisionado na formação de professores. São Paulo: Averamp, 2006.

BRASIL. Lei n. 13.415, de fevereiro de 2017. Presidência da República. Casa Civil. Subchefia para Assuntos Jurídicos. Disponível em: http//www.planalto.gov.br. Acesso em: 19 de outubro de 2020.

BRASIL. Ministério da Educação. Secretaria de Educação Básica. Orientações curriculares para o Ensino Médio. Vol. 3, Brasília, 2006. p.133. Disponível em: http://portal.mec.gov.br/seb/arquivos/pdf/book_volume_03_internet.pdf. Acesso em: 05 outubro 2020.

CALLAI, H. C. A Geografia Ensinada: os desafios de uma Educação Geográfica. In: MORAES, E. M. B. de, MORAES; LOÇANDRA, Borges de. Formação de professores: conteúdos e metodologias no ensino de Geografia. Goiânia: NEPEC, 2010.

CASTROGIOVANNI, A. C. Para entender a necessidade de práticas prazerosas no ensino de Geografia na pós-modernidade. In: REGO, N.; CASTROGIOVANNI, A. C.; KAECHER, N. A. Geografia. Porto Alegre: Artemed, 2007.

CAVAlCANTI, L. de S. Geografia e Prática de Ensino. Goiânia: Alternativa, 2002.

ESTAÇÕES ferroviárias de Campina Grande. Blog Retalhos Históricos de Campina Grande. Disponível em: <http://cgretalhos.blogspot.com/2009/10/estacoes-ferroviariasde-campina-grande.html\#.Xd8hnuhKjIU> Acesso em: 17 set. 2019.

FREITAS, F. C. C, de.; SOUSA, F. G. A. de.; FIALHO, L. M. F. Uso de tecnologias nas aulas de Geografia no Ensino Médio. In: Rev. Multidisciplinar em Educação, Porto Velho, v. 17, 2020 (653-671). 
GEONAUTA. Tirinha de Mafalda. Blog. Disponível em: $<$ http://geonauta.com.br/upload/images/questao-vestibular-nordeste-1.JPG>. Acesso em: 19 de set. de 2019 , às $20 \mathrm{~h} 44 \mathrm{~min}$.

HOLLAS, J.; BERNARDI, L. T. M. dos S. O Exame Nacional do Ensino Médio (Enem) e as competências para uma Educação Estatística Crítica. In: Ensaio: aval.pol.públ.Educ. vol.28. 2020.

ILHA das flores. Ilha das Flores. [Curta-metragem]. Direção de Jorge Furtado. Porto Alegre - RS: Casa de Cinema de Porto Alegre, 1989. Roteiro: Cecília Meireles. (15 min). Disponível em: <https://www.youtube.com/watch?v=bVjhNaX57iA $>$. Acesso em 26 de set. de 2019.

LIBÂNEO, J. C. Didática. São Paulo: Cortez, 1994.

MARTINS, D.; BIGOTTO, F.; VITIELlO, M. Geografia no Cotidiano: Ensino Médio, $2^{\circ}$ ano. 1 ed. Curitiba: Base Editorial, 2016.

MELO, F. A. de. Aulas tediosas, alunos alienados. In: PASSINI, E. Y., PASSINI, R. \& MALYSZ, S. T. Prática de Ensino de Geografia e Estágio Supervisionado. São Paulo: Contexto, 2010.

MODERN TIMES. (Tempos Modernos). Direção de Charles Chaplin. (87 min.) Preto \& Branco. EUA: Warner Bros, 1936.

MORAIS, N. R.; MELO, J. A. B. A relevância do estudo de campo no processo ensinoaprendizagem de Geografia. In: III Seminário Nacional do Ensino Médio - SENACEM e III Simpósio de Pós-Graduação em Educação da UERN: currículos, aprendizagens, saberes, v. 01, Mossoró-RN, 2013.

NASCIMENTO, M. S. Concepções acerca das geotecnologias como recurso didático para o ensino de Geografia. In: Research, Society and Development, v. 9. 2020. Disponível em: https://rsdjournal.org/index.php/rsd/article/view/2671/3229. Acesso em: 15 de outubro de 2020.

OLIVEIRA, M. L. T. de. Ensino de Geografia na contemporaneidade: o uso de recursos didáticos na sua abordagem. In: $\mathbf{X}$ Encontro Nacional de Prática de Ensino em Geografia, Porto Alegre, 2009.

PARAÍBA. O que é a Escola Integral? Governo da Paraíba. Disponível em: $<$ http://paraiba.pb.gov.br/educacao/escolas-cidadas-integrais/o-que-e-a-escolaintegral/>. Acesso em: 26 nov. 2019.

PIMENTA, S. G. Por que o estágio para quem já exerce o magistério. In.: PIMENTA, S. G. et. al. Estágio e Docência, 4ed., São Paulo: Cortez, 2009. 
PONTUSCHKA, N. N. Licenciados de Geografia e suas representações sobre o "ser professor”. In.: Terra Livre, AGB, São Paulo, n 11-12, ago. 92/ago.93 (189-207).

PRAIS, J. L. de S.; ROSA, V. F. Nuvem de palavras e mapa conceitual: estratégias e recursos tecnológicos na prática pedagógica. In.: Revista Nuances: estudos sobre Educação, Presidente Prudente/SP, v.28, n. 1, 2017, (201-219).

ROCHA, A. A. Um estudo sobre o ENEM e o currículo de Geografia no Ensino Médio. In: Giramundo, Rio de Janeiro, v. 1, 2014 (21-32).

ROSA, C. C. Geografia escolar e as recontextualizações dos conteúdos geográficos. In: FÓRUM NACIONAL NEPEG, 9., 2018. Anais. Goiânia: C\&A Alfa Comunicação, 2018.

SAIKI, K.; GODOI, F. B. A prática de Ensino e o Estágio Supervisionado. In. PASSINI, E. Y.; PASSINI, R. MALYSZ, S. T. (org.). Prática de Ensino de Geografia e Estágio Supervisionado. 2. ed. São Paulo: Contexto, 2010.

SILVA, L. A. P. e.; LEITE, C. M. C. Formação continuada em Geografia: diálogos sobre a carreira docente e o desenvolvimento profissional. In: Revista Estudo Pesquisa Ensino em Geo. v. 6, n. 9, 2019.

SILVA, J. G. da; MELO, J. A. B. de. Estágio supervisionado em Geografia e Atividades Lúdicas como proposta para dinamização das aulas. In: Revista de Geografia (Recife). v. 33, No. 2. Recife, 2016.

THE STORY OF STUFF. A História das Coisas, Direção de Louis Fox. (21 min) Disponível em: $<$ https://www.youtube.com/watch?v=7qFiGMSnNjw $>$. Acesso em 26 de set. de 2019, às 20h41min. 